\title{
The efficiency of a two-phase nozzle as a motion force for power generation from low-temperature resources
}

\author{
S. Vahaji, A. Akbarzadeh, A. Date, S. C. P. Cheung \& J. Y. Tu \\ RMIT University, Australia
}

\begin{abstract}
Two-phase nozzles could be used as energy conversion devices in geothermal total flow systems or binary fluid systems followed by a trilateral cycle for power generation. In this paper, the efficiency of such nozzles is investigated. Also, a profound research has been done on similar area in the past where mostly high pressure and high temperature energy resources were considered; so, the possibility of utilizing low-temperature energy resources remains limited in the literature. In order to bridge the knowledge gap, the feasibility of utilizing low-temperature resources for power generation is studied in this paper.

In this regards, experiments are carried out with the following conditions: a convergent-divergent nozzle is supplied with water at atmospheric pressure with various temperatures at/below $100^{\circ} \mathrm{C}$. This nozzle is connected to a tank that is evacuated by a vacuum pump. The driving force for water to flow through the nozzle is the pressure difference between atmosphere and vacuum pressure in the flash tank. As water is passed through the nozzle, the thermal energy is converted to kinetic energy as a motive force for power generation. The impulse force caused by the jet exiting the nozzle is measured and compared against the ideal case (i.e. isentropic expansion assumption) to calculate the thrust coefficient of the nozzle and evaluate the efficiency of the process. Also, the pressure and temperature profiles along the nozzle are obtained and compared against saturation pressure corresponding to measured temperatures. The results encourage the utilization of low-temperature geothermal energy resources for power generation.
\end{abstract}

Keywords: two-phase nozzle, geothermal energy, power generation. 


\section{Introduction}

Exponential increase in world population and reduced rain in certain areas of the world has led to a fresh water shortage. In addition to this, the technological advances and industrialisation has led to increased demands for power and our dependency on fossil fuels.

Considering the population growth and rapid pace of industrialization in developing countries, water shortage is a serious threat not only to the viability of the industry but also basic supply of drinking water. According to the report by the WHO (World Health Organization) and the UN, an estimated 2.6 billion people are living without improved sanitation facilities because of overexploitation and pollution of water. If the 1990-2002 trends continue, the world will miss the sanitation target of the MDG (Millennium Development Goals) by more than half a billion people (WHO and UNICEF 2004).

To solve the lack of water, many technologies have been developed over past years to separate water and salt from saline water sources. Most commonly used method is heating saline liquid water to temperatures above $100^{\circ} \mathrm{C}$ to produce large amounts of vapour under atmospheric conditions and condense the vapour to get fresh water. In this method saline water is generally heated by burning fossil fuels. Burning fossil fuels results in generating greenhouse gases, which cause another threat to the environment. The second most common method of desalination of saline water is using reverse osmosis, where saline water is pressurized to respective osmotic pressures and passed through filters to separate salt and fresh water. For seawater with an average salinity of $2.5 \%$, the osmotic pressure is $2.6 \mathrm{MP}$ which means that the pump should overcome this pressure to make the fluid flow in the reverse direction [1].

The thermal desalination process uses the phenomenon of flashing or sudden boiling due to sudden or gradual depressurisation of hot saline water. The process of flashing has been studied and investigated in the past by many researchers, and a good understanding of the flashing process has been developed [2-7]. Past studies have shown the importance of super heat and the local pressure in the process of flashing. It is shown that rate of flash evaporation rises by increasing the initial water temperature and the superheat degree [8].

In this method - Combined Desalination and Power generation (CDP) saline water is heated up to $100^{\circ} \mathrm{C}$ at atmospheric pressure. Then it is introduced into an evacuated chamber through a simple orifice shape nozzle. As a result of experiencing the pressure difference between outside and inside of the chamber, saline water forms a mixture of liquid droplets and vapour. Later, vapour is condensed on the surface of the condenser and collected in the fresh water tank. Simultaneously, the reaction force caused by high velocity of mixture entering into the vacuum chamber, could be utilized to produce power.

Following are the advantages of the CDP over the commonly used distillation or desalination methods:

1. Fresh water and power are produced simultaneously.

2. Water would be heated only up to $100^{\circ} \mathrm{C}$, which could be maintained through other methods rather than burning fossil fuels. As a result, the 
more burning fossil fuels avoided, more greenhouse gases' generation prevented.

3. It is observed that intensity of flash evaporation is faster in superheated water jets comparing water pools and also water flowing in channels [9].

Since most of the available geothermal resources all over the world and specifically in Australia are low-temperature and low quality, there is strong interest in the investigation of harvesting such energy. However, yet more attention and research is required to be done in this area. Therefore, authors of this paper have conducted experiments to enhance better understanding of this phenomenon and investigate the possibility of utilizing the energy of lowtemperature, low quality mixtures of the geothermal resources.

This paper presents the experimental performance results of water $\left(60^{\circ} \mathrm{C}\right.$ to $96^{\circ} \mathrm{C}$ ) flashing under vacuum $(5 \mathrm{kPa}-10 \mathrm{kPa}$ absolute). Flashing nozzles are often used in thermal desalination systems. An interesting application of this investigation is discussed in the paper. Reaction force produced due to the high exit velocity of the flashing (expanding) fluid is measured for different water inlet temperatures and vacuum pressures. By applying the conservation of mass and momentum and knowing the nozzle geometry, the exit velocities are estimated for the nozzle exits.

\section{Theoretical analysis of two-phase flow nozzle}

For some geothermal resources, especially lower-temperature ones, the wellhead fluid that enters the nozzle is a saturated or compressed liquid. At the vena contracta, the fluid stream accelerates and pressure energy is converted to kinetic energy due to sudden contraction. After the throat, the fluid cycles into the two-phase state.

The following assumptions are applied to obtain the main governing equations:

1. The flow is steady state and adiabatic.

2. There is no heat transfer between the nozzle and the environment.

3. The flow is horizontal and is not affected by gravity or any other force, like surface tension so that the partial pressure of the vapour phase is equal to that of liquid phase.

For the sake of better understanding of the thermodynamics of the system, $\mathrm{T}-\mathrm{S}$ diagram is shown in Fig. 1. In this figure, the isentropic condition is presented with the end point 'es' where the entropy of the fluid remains constant. In this case, the fluid leaves the nozzle with a minimum value of enthalpy and the enthalpy drop is converted to kinetic energy. Therefore, the isentropic case would offer the most ideal situation for fully converting thermal energy to kinetic energy. In isenthalpic case (end point shown as 'eh' in the Fig. 1), the enthalpy of the fluid will not change during the expansion, and hence no conversion of thermal energy to kinetic energy is expected. Real case (end point displayed as ' $\mathrm{e}$ ' in the Fig. 1) is somewhere between these two limiting conditions, where part of the thermal energy is converted to kinetic energy, and part of it is consumed for phase change inside the nozzle. 


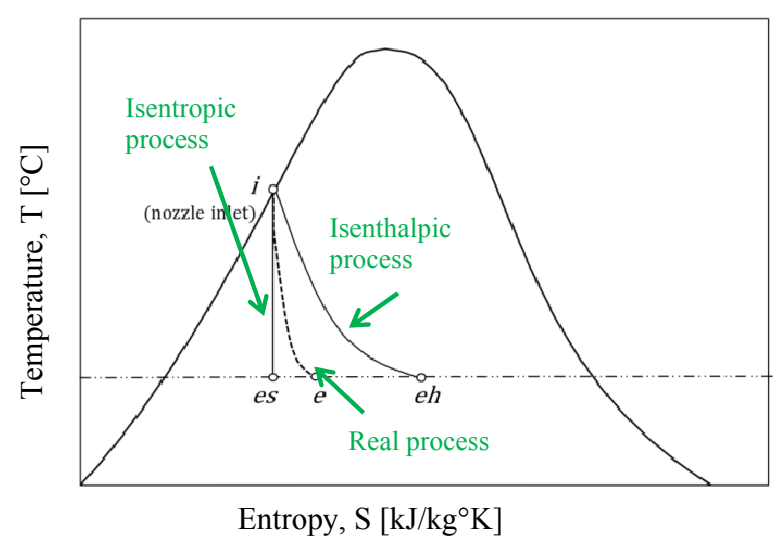

Figure 1: $\quad$ T-S diagram for subcooled/saturated liquid feeding to a two phase flow nozzle with possible scenarios as the most ideal (isentropic), fully irreversible (isenthalpic) and a real case as shown.

Now that the data is collected proper calculation needs to be done. In this section, a sample calculation based on the thermodynamics of the system (Fig. 1) is presented. By measuring the temperature of point ' $i$ ' (inlet feed water) and assuming it is saturated liquid, other thermal properties of water will be known through water thermal properties table. Since there is yet no vapour generated at this point, thermal properties will be the ones assigned to saturated liquid.

By knowing the pressure of the flashing tank (evacuated chamber), the quality of the mixture at the nozzle exit for an isentropic process is calculated as follows

$$
\begin{gathered}
\mathrm{S}_{\mathrm{es}}=\mathrm{S}_{\mathrm{i}} \\
\mathrm{S}_{\mathrm{es}}=\mathrm{S}_{\mathrm{f}, \mathrm{e}}+\mathrm{x}_{\mathrm{es}} \mathrm{S}_{\mathrm{fg}, \mathrm{e}}
\end{gathered}
$$

the quality of the mixture at point 'es' shown in Fig. 1 is obtained from

$$
\mathrm{x}_{\mathrm{es}}=\frac{\mathrm{s}_{\mathrm{f}, \mathrm{i}}-\mathrm{S}_{\mathrm{f}, \mathrm{e}}}{\mathrm{S}_{\mathrm{fg}, \mathrm{e}}}
$$

For the real case, entropy of the mixture at the exit of the nozzle will be higher than the isentropic case (refer to Fig. 1). The isentropic efficiency of the cycle indicates how far the real case from the isentropic case is. For this purpose, the quality of the mixture at the exit of the nozzle $x_{e}$, is required. In order to obtain $x_{e}$, the measured impulse force caused by the jet of the mixture after exiting the nozzle and impinging on the target plate is employed:

$$
\mathrm{u}_{\mathrm{e}}=\frac{\mathrm{F}_{\mathrm{exp}}}{\dot{\mathrm{m}}}
$$

where $u_{e}$ is the velocity of jet at the nozzle exit, $\dot{m}$ is the total mass flow rate and $\mathrm{F}_{\text {exp }}$ is the experimentally measured impulse on the target plate. 


$$
\begin{gathered}
\mathrm{h}_{\mathrm{e}}=\mathrm{h}_{\mathrm{in}}-\frac{\mathrm{u}_{\mathrm{e}}^{2}}{2} \\
\mathrm{x}_{\mathrm{e}}=\frac{\mathrm{h}_{\mathrm{e}}-\mathrm{h}_{\mathrm{f}, \mathrm{e}}}{\mathrm{h}_{\mathrm{fg}, \mathrm{e}}}
\end{gathered}
$$

Then, the isentropic efficiency is calculated from

$$
\eta_{\mathrm{s}}=\frac{\mathrm{h}_{\mathrm{i}}-\mathrm{h}_{\mathrm{e}}}{\mathrm{h}_{\mathrm{i}}-\mathrm{h}_{\mathrm{es}}}
$$

which will be equal to 0 for isenthalpic (or constant enthalpy) process and equal to 1 for isentropic process. For real case, the process is shown by the 'i-e' line for which $\eta_{\mathrm{s}}$ will be between 0 and 1 .

Thrust coefficient factor CT, is calculated from

$$
\mathrm{C}_{\mathrm{T}}=\frac{\mathrm{F}_{\mathrm{exp}}}{\dot{\mathrm{mu}}_{\mathrm{es}}}=\frac{\mathrm{u}_{\mathrm{e}}}{\mathrm{u}_{\mathrm{es}}}=\sqrt{\frac{\mathrm{h}_{\mathrm{i}}-\mathrm{h}_{\mathrm{e}}}{\mathrm{h}_{\mathrm{i}}-\mathrm{h}_{\mathrm{es}}}}
$$

The thrust coefficient factor, CT, and the isentropic efficiency of the cycle are then related according to the following equation

$$
\eta_{\mathrm{s}}=\mathrm{C}_{\mathrm{T}}^{2}
$$

\section{Experimental set-up}

\subsection{Description of experiment}

A test rig is designed to enable the experimental study on the efficiency of twophase flow nozzles under low pressure conditions. Fig. 2 shows a simple schematic of the experiment set up. Water is heated in a tank with 100 lit capacity to the boiling point at the atmospheric pressure and introduced into the flashing tank where a vacuum of $5 \mathrm{kPa}$ (absolute) is maintained. This vacuum is initially achieved by connecting a vacuum pump to the flashing tank. The pressure in the tanks is then maintained at a low value by running cooling water through a condenser coil with the total surface area of $16 \mathrm{~m} 2$.

Before hot water enters the inlet pipe, any solid impurities are filtered to prevent clogging of the nozzle. The hot water moves rapidly from the atmospheric pressure region to a very low pressure region through the converging-diverging nozzle. At the nozzle throat, the fluid is accelerated due to the sudden contraction and, therefore, experiences a sudden pressure drop. As a result of experiencing a sudden pressure drop, the fluid flash evaporates. This creates a high velocity jet of liquid and vapor mixture at a lower temperature which impinges on a target plate. In order to have a better analysis of the process, the temperature and pressure profiles along the nozzle are measured using pitot tubes and thermocouples as shown in Fig. 3. 


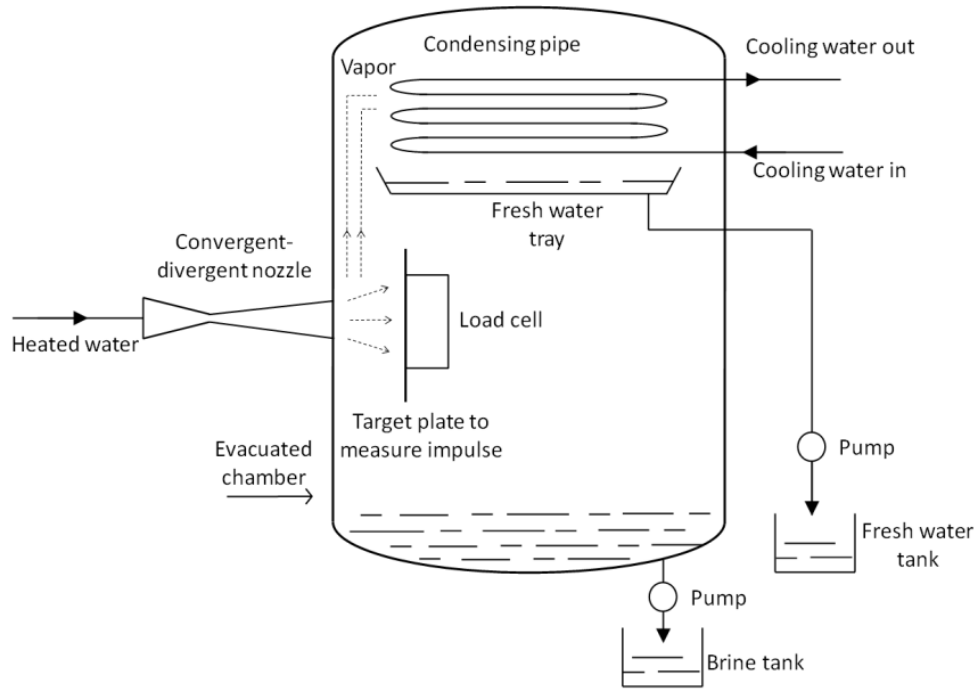

Figure 2: A simplified schematic of the experiment set up.

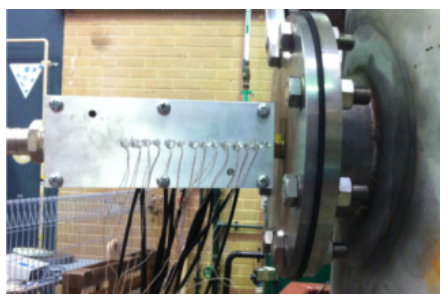

(a)

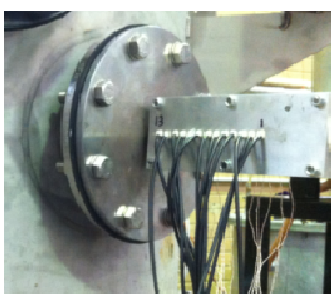

(b)

Figure 3: (a) Measuring temperature along the nozzle by T-type thermocouples, (b) measuring pressure along the nozzle using static pitot tubes.

It is assumed that a homogenous mixture of the liquid and vapour would flow out of the nozzle at very high velocities, and as a direct effect of this phenomenon, the jet will produce an impulse force $\left(\dot{\mathrm{m}} \times \mathrm{u}_{\mathrm{e}}\right)$ on the target where an equal reaction force (thrust) will also act on the stationary nozzle.

In order to capture the impulse force, a target plate in installed in the vacuum tank located in front of the nozzle exit. By installing a load cell at the back of the target plate, the impulse force is measured. Now the liquid portion of the mixture will eventually fall to the bottom plate and is collected in the brine tank, whereas the vapour would rise in the chamber. It is then condensed on the surface of the condenser and gets collected in the freshwater tank.

It is the main focus of this experimental study to achieve maximum impulse force caused by the jet exiting the nozzle. 


\section{Results and discussion}

\subsection{Calculated results}

In Table 1, a summary of experimental conditions and corresponding calculation results is presented. The following points are proved by the results shown in this table:

- By increasing the inlet temperature, the following parameters increase considerably: the nozzle efficiency, the thrust coefficient, the quality of mixture exiting from the nozzle and the impulse force caused by the jet.

- Mass flow rate slightly decreases by increasing the inlet temperature. The reason of a slight change could be explained by the square root effect that appears in the relation between mass flow rate and pressure drop.

Table 1: Experimental conditions and corresponding calculation results.

\begin{tabular}{|c|c|c|c|c|c|c|c|c|c|}
\hline Experiment & $\begin{array}{l}\text { Feed } \\
\text { water } \\
\text { temp. }\end{array}$ & $\begin{array}{l}\text { Back } \\
\text { pres. }\end{array}$ & $\dot{\mathrm{m}}$ & $\mathrm{F}_{\text {exp }}$ & $u_{e}$ & $\mathrm{~h}_{\mathrm{e}}$ & $\mathrm{x}_{\mathrm{e}}$ & $\eta_{\mathrm{s}}$ & $\mathrm{C}_{\mathrm{T}}$ \\
\cline { 2 - 10 } & $\left({ }^{\circ} \mathrm{C}\right)$ & $(\mathrm{kPa})$ & $(\mathrm{kg} / \mathrm{s})$ & $(\mathrm{N})$ & $\begin{array}{l}(\mathrm{m} / \mathrm{s}) \\
\text { Calc. } \\
\text { from } \\
\text { Eq. 4 }\end{array}$ & $\begin{array}{l}(\mathrm{kJ} / \mathrm{kg}) \\
\text { Calc. } \\
\text { from } \\
\text { Eq. 5 }\end{array}$ & $\begin{array}{l}\text { Calc. } \\
\text { from } \\
\text { Eq. 6 }\end{array}$ & $\begin{array}{l}\text { Calc. } \\
\text { from } \\
\text { Eq. 7 }\end{array}$ & $\begin{array}{l}\text { Calc. } \\
\text { from } \\
\text { Eq. 8 }\end{array}$ \\
\hline exp. A & 60.5 & 5.8 & 0.093 & 2.8 & 30.0 & 218.9 & 0.029 & 0.241 & 0.491 \\
\hline exp. B & 80.0 & 7.7 & 0.075 & 5.2 & 69.2 & 306.0 & 0.056 & 0.352 & 0.593 \\
\hline exp. C & 96.0 & 8.8 & 0.072 & 7.6 & 105.7 & 371.7 & 0.079 & 0.420 & 0.648 \\
\hline
\end{tabular}

\subsection{Pressure profiles}

In Fig. 4, the pressure profiles of the nozzle for three different conditions (mainly inlet temperatures and slight variation in back pressure) are presented. For the sake of better visualization, the convergent-divergent nozzle geometry profile is also depicted. In these figures, the nozzle throat indicates the 0 coordinate of the horizontal axis. It could be seen that the increase of inlet temperature will result in higher pressure downstream the throat which leads to lower mass flow rate (m). This is explained by the fact that with higher inlet temperature, the rate of phase change is higher, the velocity is higher, and pressure drop is lower. Lower pressure drop in the nozzle means higher pressure downstream of the throat.

As could be seen from the Fig. 4, the fluid experiences a large pressure drop at the throat. This agrees well with similar results experienced in previous investigations [10] with similar experimental set-up and approximate nozzle geometry, but higher inlet and higher back pressures. 


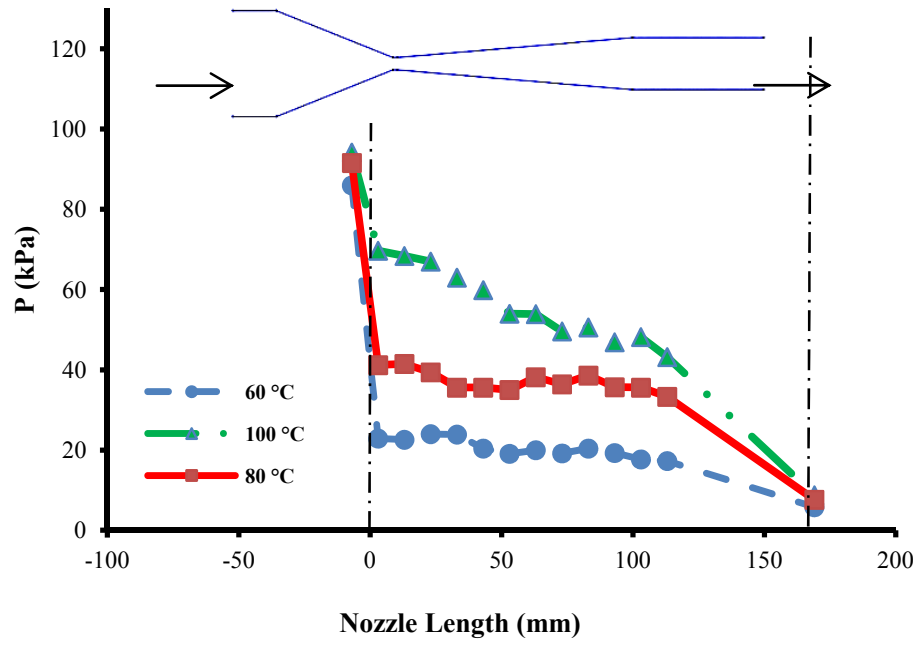

Figure 4: Pressure profiles along the nozzle for three different conditions.

\subsection{Thrust coefficient and isentropic efficiency of the nozzle}

In Fig. 5, the thrust coefficient, $C_{T}$, and isentropic efficiency, $\eta_{s}$, of the nozzle in percentage described in section 3.2 and calculated in Table 1 are depicted against feed water temperature for different experimental conditions. The thrust coefficient and isentropic efficiency of the nozzle are calculated from Eq. (8) and 7 , respectively. The calculations prove that Eq. (9) is valid for the assumption of no slip velocity, i.e. $\mathrm{u}_{\mathrm{l}}=\mathrm{u}_{\mathrm{g}}$.

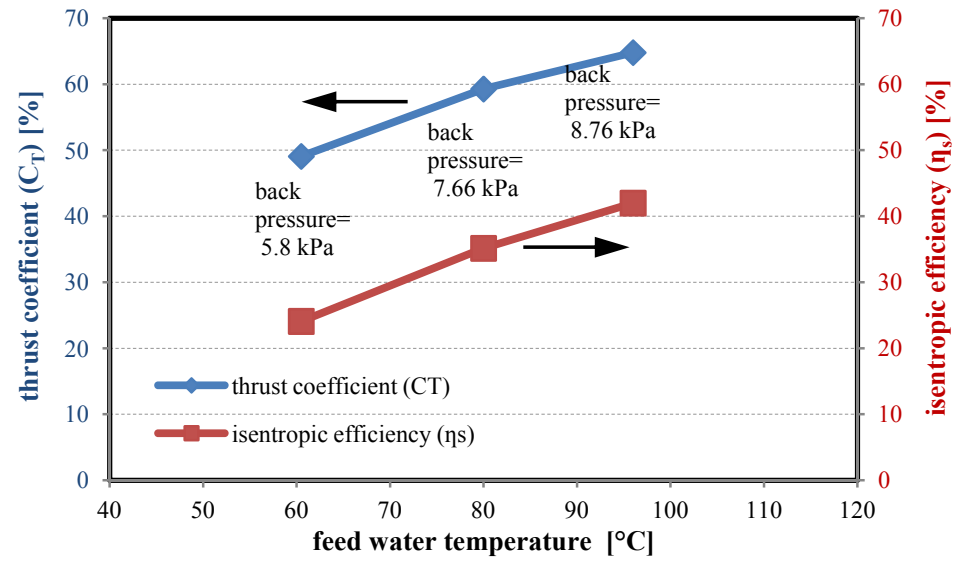

Figure 5: Nozzle isentropic efficiency and thrust coefficient vs. feed water temperature. 
It is observed that by increasing the feed water temperature and keeping the back pressure almost similar (please note that the inlet condition is at atmospheric pressure, and a slight change in back pressure around $3 \mathrm{kPa}$ is not influential on the results), the efficiency of the nozzle is increased. The trend that this figure is presenting, suggests that by having similar experimental conditions, probably the maximum nozzle efficiency could be achieved by introducing the feed water with temperature around $130^{\circ} \mathrm{C}$.

Fig. 6 compares the thrust coefficient in percentage vs. back pressure in different experiments of Alger [11]. In the same figure results of the current work are presented. It should be noted that the data presented by Alger [11] refer to experiments where the fluid is at a higher state of energy at its entrance to the nozzle compared with the present work. The experiments conducted by Alger [11] were involved with the quality of 10 to 15 percent steam; whereas, in the present work, the fluid has a quality of zero as it is substantially subcooled (up to $40^{\circ} \mathrm{C}$ ) at its entrance to the nozzle. This explains lower thrust coefficient achieved in the current work. Despite having a quality of the mixture equal to zero at the nozzle entrance, still about 60 percent of thrust coefficient is achievable. This result encourages utilizing the low-temperature, low quality resources for energy harvest.

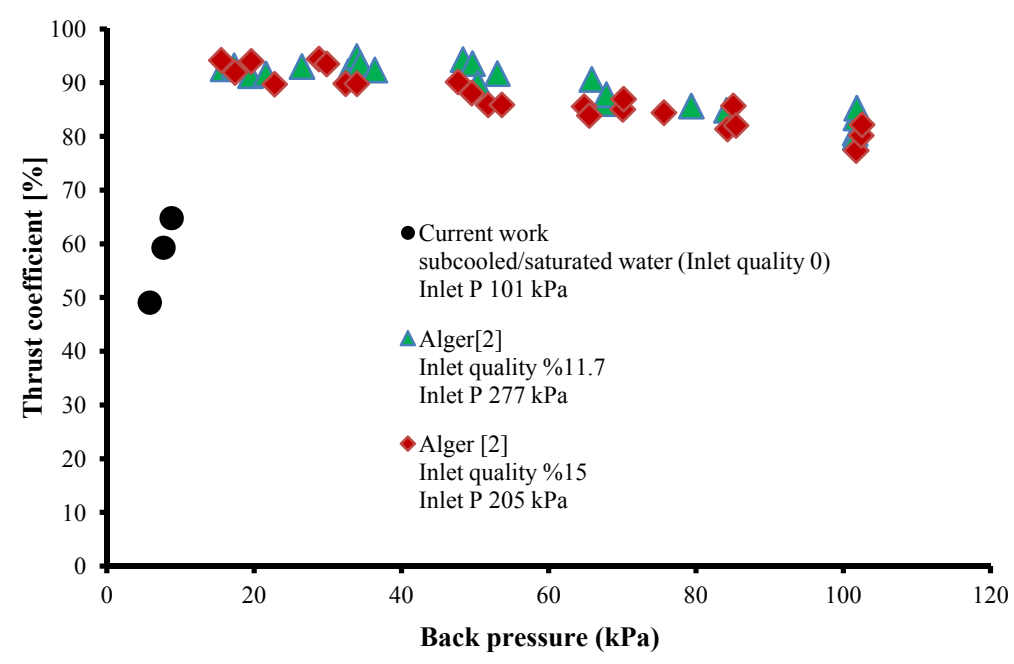

Figure 6: Thrust coefficient percentage vs. back pressure $(\mathrm{kPa})$.

The above mentioned idea (influence of inlet quality on nozzle efficiency) was investigated by Bunch et al. [12] where the feeding fluid was seeded with tiny bubbles. Their results show that as the nozzle inlet quality decreases, the thrust coefficient of the nozzle decreases as well. Thrust coefficients are generally considered being decreased markedly when water droplets are present [13]. However, the work presented in [11] shows that high performance nozzles 
with thrust coefficients up to and probably beyond 0.94 can be designed for inlet quality (vapour mass fraction) as low as 12 percent (whereas, in our case the inlet quality is zero (subcooled/saturated liquid)). Still with zero quality we could achieve around 60 percent thrust coefficient which is another encouragement for utilization of such resources.

The low efficiency of the nozzle indicates that less vapour is produced than expected. The assumption of the calculations is that a homogeneous mixture is present along the nozzle; however, a lump of liquid enters the nozzle with higher pressure than saturation pressure. Also, probably there is heat transfer between the nozzle and the environment which leads to non-adiabatic condition process. Therefore, not all the heat will evaporate the liquid which leads in having a less efficient nozzle.

Under-expanded situations when the liquid has not had the chance for the possible complete phase change, results in a pressure at the exit that is higher than the chamber pressure. Since this condition does not represent a complete expansion (all available thermal energy has not been converted into kinetic energy) the nozzle is inefficient when operating in this mode. Also, in the operating conditions where no shock wave or expansion wave is present, the highest thrust value could be achieved.

\section{Conclusion and future work}

Experiments on two-phase flow in a converging-diverging nozzle have been carried out with different fluid conditions. Results indicate that with temperature sources of feed water as low as $60^{\circ} \mathrm{C}$, with no bubbles at inlet, thrust coefficient as high as $50 \%$ could be achieved. It shows that nozzles, whether stationary or rotary, could be used to generate force as a means of energy conversion device of low-temperature heat as low as $60^{\circ} \mathrm{C}$ into mechanical power with reasonable efficiencies. This would open up applications of these conversion devices in better utilization of heat whether in geothermal, solar or waste heat resources. Obviously by further research one could be able to achieve better efficiencies of nozzle. Following is a list of the works that could be done in the future:

- Change of chamber pressure from minimum saturation pressure, which could be achieved by a good condensation facility, to atmospheric pressure.

- Run the experiments at different varying nozzle length (from the throat to the exit opening) and different area ratios of the throat to the exit area.

- As discussed in section 4.3 , it is encouraged to carry out the experiment with feed water around $130^{\circ} \mathrm{C}$ to investigate the possibility of achieving the maximum nozzle efficiency. 


\section{Nomenclature}

\begin{tabular}{|c|c|}
\hline$C_{T} \quad$ thrust coefficient & Subscripts: \\
\hline force $(N)$ & property at nozzle exit \\
\hline specific enthalpy $(\mathrm{kJ} / \mathrm{kg})$ & exp experimental \\
\hline mass flow rate $(\mathrm{kg} / \mathrm{s})$ & property of liquid at saturated \\
\hline pressure $(\mathrm{kPa})$ & condition \\
\hline entropy $\left(\mathrm{kJ} / \mathrm{kg}^{\circ} \mathrm{K}\right)$ & gas, property of vapour at saturated \\
\hline temperature $\left({ }^{\circ} \mathrm{C}\right)$ & condition \\
\hline velocity $(\mathrm{m} / \mathrm{s})$ & property at nozzle inlet \\
\hline quality of the mixture & liquid \\
\hline Greek symbols: & isentropic process \\
\hline $\begin{array}{l}\text { isentropic efficiency, energy } \\
\text { conversion coefficient }\end{array}$ & $\begin{array}{l}\text { sat } \text { saturation } \\
\text { th } \text { theoretical }\end{array}$ \\
\hline
\end{tabular}

\section{Acknowledgements}

We acknowledge that this project is supported by Australian Research Council (ARC) Linkage under project ID. LP0990691. We also appreciate the financial support of Greenearth Energy Ltd, Australia.

\section{References}

[1] A. M. Thomso, Reverse-Osmosis Desalination of Seawater Powered by Photovoltaics Without Batteries, 2003.

[2] R. Brown and J. L. York, Sprays formed by flashing liquid jets. AIChE Journal, 8(2): pp. 149-153, 1962.

[3] A. K. El-Fiqi, N. H. Ali, H. T. El-Dessouky, H. S. Fath and M. A. ElHefni, Flash evaporation in a superheated water liquid jet. Desalination, 206(1-3): pp. 311-321, 2007.

[4] S. Gopalakrishna, V. M. Purushothaman and N. Lior, An experimental study of flash evaporation from liquid pools. Desalination, 65: pp. 139-151, 1987.

[5] Y. Kitamura, H. Morimitsu and T. Takahashi, Critical superheat for flashing of superheated liquid jets. Industrial \& Engineering Chemistry Fundamentals, 25(2): pp. 206-211, 1986.

[6] S. Mutair and Y. Ikegami, Experimental study on flash evaporation from superheated water jets: Influencing factors and formulation of correlation. International Journal of Heat and Mass Transfer, 52(23): pp. 5643-5651, 2009.

[7] R. Peterson, S. Grewal and M. El-Wakil, Investigations of liquid flashing and evaporation due to sudden depressurization. International journal of heat and mass transfer, 27(2): pp. 301-310, 1984. 
[8] S. Mutair and Y. Ikegami, Experimental investigation on the characteristics of flash evaporation from superheated water jets for desalination. Desalination, 251(1-3): pp. 103-111, 2010.

[9] O. Miyatake, T. Tomimura, Y. Ide, M. Yuda and T. Fujii, Effect Of Liquid Temperature On Spray Flash Evaporation. Desalination, 37(3): pp. 351366, 1981.

[10] J. Ohta, T. Fujii, K. Akagawa and N. Takenaka, Performance and flow characteristics of nozzles for initially subcooled hot water (influence of turbulence and decompression rate). International journal of multiphase flow, 19(1): pp. 125-136, 1993.

[11] T. Alger, Performance of two-phase nozzles for total flow geothermal impulse turbines, 1975, California Univ., Livermore (USA). Lawrence Livermore Lab.

[12] T. K. Bunch, A. A. Kornhauser and M. P. Alexandrian. Efficiency of a flashing flow nozzle. Proc. of the Energy Conversion Engineering Conference, 1996. IECEC 96. Proceedings of the 31st Intersociety. 1996. IEEE, Year.

[13] A. Austin and A. Lundberg, A comparison of methods for electric power generation from geothermal hot water deposits. ASME Paper, (74-WA), 1974. 